\title{
Academic Freedom in Higher Education Within a Conservative Sociopolitical Culture
}

\author{
Robert L. Williams
}

Published online: 18 April 2006

\begin{abstract}
This paper examines the potential threat that a conservative sociopolitical culture poses to academic freedom in state colleges and universities. Already a number of states are considering legislation that would restrict professors' rights to discuss political issues within their classes, especially political issues having religious or moral implications. The proposed legislation would permit professors to discuss political issues substantively linked to the official subject matter of courses, but would limit professors' role in such discussion to one of political neutrality. The paper addresses the possibility of discussing controversial sociopolitical issues in college and university classes without alienating an institution's external support base.
\end{abstract}

KEY WORDS: Academic freedom; Political conservatism; Political liberalism; Information sources.

The current controversy in the United States about patriotism versus tolerance for dissent may eventually impact the level of academic freedom permitted in American higher education. Although higher education typically is regarded as the ultimate arena in society for open discussion of controversial issues, public institutions funded by conservative constituencies may not be guaranteed this level of open dialogue in the future. Historical precedent documents that such external restriction can happen. In fact, Bollinger (2005), President of Columbia University, has described blatant government invasion into academic freedom during World War I and the McCarthy era. During the latter period more than 600 professors and teachers were fired because of alleged communist ties. In the early twenty-first century, professors' expression of viewpoints counter to official government policies might be viewed as less than patriotic and even as an adverse influence in society.

Robert L. Williams holds the M.A. in Counseling and Guidance and the Ph.D. in Educational Psychology from the George Peabody College for Teachers. He is Professor of Educational Psychology and Counseling with primary affiliation in the School Psychology Program at the University of Tennessee. His current research relates to the improvement of instruction in higher education and includes the areas of critical thinking, notetaking, multiple-choice testing, vocabulary development, students' information sources, and student motivation. Professor Williams can be contacted at bobwilliams@utk.edu. 
Further complicating open discussion of sociopolitical issues within higher education is the relative recent marriage between religious fundamentalism and conservative politics, a prominent sociopolitical movement promoting a strong moral agenda for the political structure of the country. Although religious beliefs and moral perspectives typically might be considered inappropriate for discussion within most college and university classes, separating contemporary political issues from religious and moral considerations could prove untenable. Certainly, such an artificial separation would dampen the fervor of political discussion within higher education.

\section{The Political Challenge to Academic Freedom}

Determining what sociopolitical issues professors can legitimately discuss and how they can appropriately discuss those issues is likely to become increasingly problematic within higher education. Certainly, voices are emerging from both the political constituencies and the higher education cultures of various states that suggest this debate is imminent and may challenge the core concept of academic freedom. For example, an organization calling itself "Students for Academic Freedom," a student-based national network headquartered in Washington, DC, questions whether professors should be allowed to express viewpoints regarding any political, religious, or moral issues not substantially related to the official subject matter of their courses. Even more objectionable to this group is professorial expression of political, religious, or moral views without giving students the opportunity to challenge those views.

An "Academic Bill of Rights" developed by Students for Academic Freedom explicitly prohibits professors from using "their courses for the purpose of political, ideological, religious or anti-religious indoctrination" (Academic Bill of Rights, n.d., p. 2). The worst abuse would be for professors to allow students' political or religious beliefs to influence assignment of grades. The organization "Students for Academic Freedom" currently has chapters on over 150 campuses in the United States and is pushing its Academic Bill of Rights as the appropriate basis of institutional policy and state laws defining the purview of academic freedom for both faculty and students (Bollinger, 2005; Students for Academic Freedom, 2005).

These political concerns are gaining impetus nationally, with approximately 20 states advancing legislation that would restrict 
professors' right to discuss political, religious, and moral issues unless their courses are officially designated as encompassing those issues (Bollinger, 2005; Don't Let Lawmakers, 2005). For example, a bill under consideration in the Tennessee legislature in 2005 would require professors to refrain from introducing political or religious topics into their classes when such topics are "substantially unrelated to the subject matter of those courses" (Campfield \& Finney, 2005, p. 1). Furthermore, even if political and religious issues are considered germane to the subject matter of particular courses, the bill would require institutions to "maintain a posture of neutrality with respect to substantive political or religious disagreements, differences, and opinions ..." (p. 2).

This concern about the rights of professors to express their viewpoints publicly on political, religious, and moral issues appears to be coming largely from conservative political groups (such as the Center for the Study of Popular Culture). This concern is anchored in the discrepancy between political perspectives of many professors and the views of their constituencies (e.g., elected officials, students, and students' parents). Several sources have documented that professors tend to have a liberal political orientation, whereas the current political establishment in the United States is more politically conservative than liberal. Klein and Western (2004) found that democrats outnumbered republicans by close to 9:1 across a variety of departments in two elite western universities (University of California, Berkeley, and Stanford University). The combined universities' disparity in the political ratios (democrats per republicans) for academic disciplines ranged from a low of 5:1 in professional schools and 8:1 in hard sciences and math to a high of 16:1 in the social sciences and 22:1 in the humanities (extrapolated from p. 25 in the Klein and Western report).

The overall disparity between democrats and republicans on college and university faculties has been confirmed by a number of other recent studies using surveys and voter-registration data (Horowitz \& Lehrer, 2002; Klein \& Stern, 2004/2005; Light, 2001). For example, a nationwide survey conducted by the Higher Education Research Institute at UCLA in 2001-2002 showed that $18 \%$ of college faculty identified themselves as conservative and $48 \%$ as liberal (Lindholm, Astin, Sax, \& Korn, 2001-2002). However, compared to survey data from 1989, the movement toward liberalism has been greater for female than for male faculty members.

In contrast to the political demographics of higher education faculties, the percentages of registered democrats and republicans tend to be about equal in the general population (CNN, 2004; Horowitz \& Lehrer, 
2002). Undoubtedly, in more religiously conservative southern states (which historically had voted democratic), voting patterns now strongly favor republican candidates. In general, many individuals who typically had voted democratic now see themselves as politically conservative, presumably because of religious considerations. For example, $21 \%$ of the general population who voted in the 2004 presidential election identified themselves as liberals and $34 \%$ as conservatives, percentages that do not match the equivalent percentages of registered democrats and republicans on a national basis (CNN, 2004). The ratio between conservatives and liberals in the general population would likely be much greater in the south than in most other regions of the country (especially the northeast and the far west). Hence, predominantly liberal state institutions of higher learning in the south are dependent on predominantly conservative political constituencies for much of their financial support.

Highly conservative politicians and citizens are not the only skeptics about state institutions viewed as liberal; conservative students may resist being exposed to information and viewpoints counter to their political/religious beliefs. For example, at the University of North Carolina some students sued over a reading assignment perceived as offensive to their Christian values (Pope, 2004). Ayers (1996) claimed that "a student is endowed with the rights to confront an educator if he or she believes that immoral or demeaning material is being presented in class" (p. 8). Although professors might be inclined to avoid religious issues in class discussions, the bonding between Christian fundamentalism and political conservatism makes religion hard to circumvent within political discussions. The claim by this political/religious coalition that they represent pivotal moral values for our government adds morality to the mix of pertinent political issues. Thus, it would be difficult for college classes to discuss our nation's current political agenda without addressing the religious and moral underpinnings of that agenda.

\section{An Equitable Climate for Discussing Controversial Political Issues}

The concerns of political and religious conservatives should not be dismissed by higher education. First, is it reasonable to expect that conservative politicians would increase or even maintain appropriations for a higher education system seen as hostile to their viewpoints? Secondly, teachers (including college and university professors) have 
historically enjoyed a high level of credibility among the general public. A relatively recent Harris poll indicates that teachers are the professionals the public views as most likely to tell the truth (Fish, 2003). Teachers at all educational levels should work very hard to preserve that level of perceived credibility. To maintain an image of credibility and fairness, how can teachers best determine what sociopolitical issues are appropriate for class discussion, and how can they most effectively engage students in equitable discussion of those issues?

\section{Determination of Appropriate Issues for Class Discussion}

A perspective of academic freedom embraced by many professors is that institutions of higher learning should foster open discussion of virtually any societal issue. Neither teachers nor students should be intimidated about discussing issues that might be considered off limits in other spheres of society (e.g., church, business). Anything less than open inquiry would limit examination of societal values, diminishing the possibility that higher education will be a catalyst for change within society. But does this notion of academic freedom mean that teachers and students should be free to discuss any issue at any time, in any class, and in any way they wish? Or, would some possibilities (e.g., existence of God, inspiration of sacred writings) be inappropriate for discussion in most classes in publicly funded institutions?

One issue on which conservative politicians and liberal professors are likely to agree is that discussion of sociopolitical issues should be substantially related to the official subject matter of courses. However, the phrase "substantially related" may be less clear than appears on the surface. Within this framework, a political science course would appear a far better context in which to discuss political issues than a mathematics course. Likewise, a religious studies course might constitute a better milieu for discussing religious fundamentalism than an English course. However, because most institutions of higher education have a relatively small percentage of courses specifically designed to explore political, religious, and moral issues, restricting discussion of such issues to these courses would greatly diminish their visibility within higher education. Most likely, professors in many subject areas feel their subject matter should be related to cuttingedge societal issues. That being the case, these professors need to define upfront how exploration of such issues relates to the overall theme of 
their courses and clearly alert students to those connections via the course catalog and course syllabus.

\section{Instructor Role in Discussion of Controversial Issues}

The instructor's primary role in leading class discussions about societal issues is to challenge students to consider alternative viewpoints without either overwhelming or antagonizing the students. Both student reactions may foreclose consideration of alternative perspectives of an issue. Although it is appropriate for an instructor to raise questions about virtually any controversial issue related to one's subject matter, the questions should target both sides of an issue. Also, questions should best be asked without implying acceptable answers: "What is your belief about ...?" would typically be better wording than "Don't you believe that ...?" It is also preferable for questions to target concepts rather than personalities. "What are the pros and cons of our nation's pulling out of the Kyoto treaty on greenhouse gaseous emissions?" would likely produce less inflammatory discussion than asking, "Did George Bush exercise good or poor judgment in pulling the United States out of the Kyoto treaty?" In general, building discussions around controversial issues may lead to more rational problem solving than focusing the discussion on controversial persons. Nonetheless, discussion of controversial issues can lead to some strong student pronouncements. Thus, a vital part of this discussion would be to ask students how they arrived at their various positions. By articulating how they came to their views and then listening respectfully to other students' rationale for their views, students may discover that some of their sociopolitical views warrant reconsideration.

In discussing debatable issues, instructors may elect to add their own views to the class discussion, but this should be done with great care. Statement of one's viewpoint early in a discussion may discourage conversation counter to that view. Actually, if instructor questioning can lead to student expression of the critical dimensions of a complex issue, it may be unnecessary for the instructor to state his or her personal view. Admittedly, an instructor's perspective sometimes can add clarity and depth to a discussion. Bollinger (2005) has taken the position that "we should not accept the argument that professors are foreclosed from expressing their opinions on the subject in the classroom ... The question is not whether a professor advocates a view but whether the overall design of the class, and course, is to explore the full range of the complexity of the subject" (p. 11). In principle, 
instructors of either a liberal or conservative political persuasion could cultivate a discussion climate in which all important perspectives of controversial issues are equitably addressed.

If and when instructors add their perspective to discussion of a debatable issue, the wording of their contribution is pivotal to its effect on the discussion. The primary question is whether the instructor's wording impedes further discussion or illuminates additional possibilities for discussion. For example, an instructor can add a perspective to a discussion without owning that perspective. Saying, "Another viewpoint is ..." may be preferable to saying, "My viewpoint is ..." Students may feel more comfortable in taking issue with a point of view to which the instructor claims no special allegiance. What should be avoided at all cost is an instructor's framing a conclusion as the final word or ultimate truth about an issue. In this vein, Bollinger cautioned that professors must resist "the temptation to use the podium as an ideological platform, to indoctrinate a captive audience, to play favorites with the like-minded and silence the others" (p. 10). The instructor need not be neutral in stating a personal view, but the instructor must be fair-minded in facilitating discussion conducive to the expression of a wide range of views.

One way an instructor can be quite proactive in promoting balanced discussion is to present literature on different sides of targeted issues, as well as credible research addressing those issues. The former is intended to challenge students to consider views that may be different from their own. Otherwise, as long as students read only literature consistent with their personal views, they are unlikely to seriously reevaluate those views. Examination of credible research on controversial issues is particularly important, given that discussion of such issues often is characterized by strong opinions with little empirical basis. However, determining whether an alleged research finding is credible will not be a simple judgment. Who did the research and how they did the research will be critical issues in making that determination. Was the research slanted to support a particular political perspective? Was the research published in an independent professional journal that has rigorous blind review of submitted manuscripts?

One of the most publicized aspects of the 2004 presidential election was the impact of Christian evangelicals on the outcome of the election, with the evangelicals giving primacy to moral values in the U.S. society. Thus, a potentially sensitive, but important, question for student consideration in social science courses would be what psychological 
characteristics and sociopolitical perspectives led evangelicals to prefer one candidate over the other. Fortunately, recent research has addressed the association between religious conservatism and a variety of psychological characteristics (e.g., authoritarianism and prejudice) and sociopolitical values, including militarism and respect for civil liberties (Altemeyer, 2003; Altemeyer \& Hunsberger, 1992; Reimer \& Park, 2001; Williams, Bliss, \& McCallum, in press). Such research could be introduced into a class discussion without the instructor's attaching a value judgment to the documented empirical relationships (i.e., the findings could be examined without the instructor's using them to support or attack conservative religious beliefs). Students would be invited to question the validity, generalizability, and utility of the research findings, speculating as to what might have accounted for the observed empirical relationships and what use should be made of the findings.

If moral development issues are introduced in class discussion, Kohlberg's (1987) model of moral development could provide a conceptual framework for that discussion. Rather than simply presenting Kohlberg's model in an abstract fashion, the instructor could link the model to sociopolitical perspectives (e.g., conservatism vs. liberalism, religious fundamentalism vs. nonfundamentalism). Although students could be asked to speculate on the connections between Kohlberg's model and a variety of sociopolitical perspectives, scientific research on these connections would provide an even better information base for the discussion (e.g., Copeland, 1995). Again, students would be invited to comment on the adequacy of Kohlberg's model and the adequacy of the research connecting that model to moral issues extant in current sociopolitical discussion in the U.S. society.

\section{Discussion Framework and Guidelines}

One of the primary objectives of discussing controversial issues is to help students understand and appreciate viewpoints different from their own. One effective framework for achieving this objective is an arrangement called structured controversy (Herreid, 1996). In this arrangement, students are initially assigned different positions on an issue. The assigned position may be different from the student's actual viewpoint. After presenting the evidence for their assigned positions, students exchange positions and present the opposite viewpoint. Structured controversy can also be done on a paired-group basis, with each group (rather than each individual) initially assigned a position 
(D'Eon \& Proctor, 2001). After presenting its assigned viewpoint to another group and listening to that group's presentation of an opposing view, each group is then paired with a different group to present the view opposite its original assignment. In this case, the group can use what it learned from the initial group interchange to bolster its case for the opposite position in subsequent discussion with another group. The group likely would be more comfortable in presenting its case to a new group than to the same group from which it derived some of its supportive information.

In addition to exposing students to the evidence on both sides of a controversial political issue, it is important to develop discussion guidelines that will help students understand and appreciate contrasting evidence. Students are exposed to many nonproductive political discussions on TV that denigrate opposing evidence, often inflaming more than informing. Many such discussions are characterized by poor listening, overstatements, and belligerent comments. The intent is to discredit not only the other person's view but also the credibility of that person. Neither participants nor viewers are likely to change their position as a result of such discussions. In fact, abrasive and inflammatory discussions on TV are likely to solidify the views of both participants and viewers. The only redeeming virtue of such discussions is that they may help the undecided viewer reach conclusions about controversial issues. However, those conclusions may be based more on style than substantive support for each position.

A foundational skill for establishing a discussion climate conducive to productive examination of controversial issues is active listening (i.e., verbally responding to another's view in a way that communicates one's understanding of that view). Inviting others to express their views and then listening without interruption as they articulate those views are matters of personal courtesy that should characterize all discussion of controversial issues. However, simply letting others talk does not ensure active listening. Students also need to communicate verbally that they accurately understand what others are saying. Students should be assured that active listening to another's view is not synonymous with endorsing that view. Given that disagreement is often precipitated by a misunderstanding of another's viewpoint, active listening at least serves the purpose of clarifying the views with which one may disagree. In reality, fully understanding another's viewpoint and the support for that view increases the chances of movement toward that view. As long as an opposing view is poorly understood 
or misrepresented, there is virtually no chance of openness to that view.

Another basic skill for achieving productive sociopolitical discussion is to speak in measured, evidential terms. Precisely stating one's position on an issue and the rationale for that position has a far different effect on discussion than exaggerating the merits of one's own view and demonizing the opposing viewpoint. In fact, stating one's views with some degree of tentativeness may facilitate more open discussion than stating one's views emphatically. Prefacing a statement of one's position with the comment, "I'm inclined to believe ...," or "my current perspective is ..." suggests the possibility that one may be willing to consider other viewpoints. On the other hand, beginning a statement with the pronouncement that "my position has always been ..." or "the truth of the matter is ..." gives the impression one may not have considered or be willing to consider evidence contrary to his or her position. Speaking in measured terms is not a skill that naturally evolves in group discussion of controversial issues. That skill must be modeled and explicitly taught by the instructor for most students to respond to one another's views in a respectful and measured fashion.

\section{Sources of Credible Information}

One of the most critical steps in reaching tenable conclusions about controversial issues is having a reliable information base for those conclusions. Unfortunately, in the areas of politics and religion, many base their conclusions on ideology and only acknowledge information that supports those conclusions. A better approach would be to first look at the evidence regarding targeted issues and then base conclusions on that evidence. However, it would be unrealistic to expect most students to have taken this approach in arriving at their positions on controversial political issues. In many cases, students cannot identify the principal informational sources for their beliefs (Bain, Williams, Isaacs, \& Williams, in press). In fact, they may be so poorly informed about politics that they do not even have a position on some of the most critical issues. In such cases, the teacher has an opportunity to create an atmosphere of information-seeking that can lead to informed rather than speculative conclusions.

Students will not be equally receptive to building solid information bases for their political conclusions. For example, students high in critical thinking skills (i.e., adept at logically linking evidence 
to conclusions) make better progress in evaluating the accuracy of content claims in a course than those low in critical thinking. Plus, students high in critical thinking are more likely than those low in critical thinking to increasingly base their conclusions on professional sources of information (e.g., published research, college courses) than on the popular media, views of acquaintances, or purely personal experiences (Williams, Bain, Stockdale, Isaacs, \& Williams, 2003).

Although the professional research literature would likely constitute the most valid source of information about political issues, the time required to review articles for publication usually means that information in the professional literature will be a year or so behind current political events. Obviously, the most current information about political issues will come from the media (e.g., television, the Internet, magazines, and newspapers). Although some news reports are balanced and accurate, others are vulnerable to political bias. For example, despite their claims to the contrary, some TV networks slant their news coverage to support a particular political party (Paul \& Elder, 2003). Identifying the political biases of various networks would be a useful starting point in helping students become discriminating consumers of the news. However, rather than advising students to watch some networks and avoid others, a better way to promote balanced assimilation of the news is to suggest that students watch a variety of networks, taking note of how these networks portray the same political events (e.g., facets of the events emphasized on some networks but minimized on others, favorable descriptions of the events on some networks but unfavorable on other networks).

Of the networks that give primacy to political news, the C-Span channels appear to do the best job in representing a diversity of political views in a first-hand fashion. For example, one is able to view congressional hearings without depending on a politician's or reporter's interpretation of what occurred at those hearings. Plus, when individuals of different political persuasions are interviewed on CSpan, the tone of the interviews is likely to be more civil and respectful than when such interviews occur on the mainstream news channels (e.g., Fox, CNN). And when listeners are invited to call in (which is often done on C-Span), an equal number of calls are taken from republican and democratic viewers. Of all the major TV channels, C-Span may be the best model for constructive political discussion in the classroom. Certainly, viewing C-Span programs would help students become better informed about political issues. 


\section{The Challenge of Higher Education: Reflecting Societal Values or Changing Societal Values?}

One of the revered notions of public education is that it constitutes the principal vehicle for promoting and sustaining the basic values in society. As societal values change, schools are expected to reflect those changes: society changes first, and then schools follow. According to this notion, the basic purpose of schooling is to maintain the societal status quo (Tozer, Violas, \& Senese, 1995). In contrast to the notion of schools as the repository of societal values, Ayers (1996) proposed that "ultimately, academic freedom is a mechanism with which schools may induce social reform" (p. 5). Within the framework of academic freedom, the schools represent the major avenue within a culture for changing societal values.

Probably most professors, especially in the liberal arts and social sciences, interpret their mission as challenging and changing the values of their students. Because many of these young people will eventually become leaders in society, changing their values in the college years will ultimately translate into changing society. Given that a majority of college professors embrace a liberal political orientation that explicitly or implicitly may be revealed in class discussions, one would expect students to become more liberal during college. An early study done by Chickering (1970) reported that college students did change in the direction of liberalism, but that change was greater for men than women. The amount of change toward liberalism varied considerably from institution to institution. Not surprisingly, the percentage of peers embracing liberal views, the amount of student-faculty contact, use of discussion rather than lecturing in class, and de-emphasis on grades as a reason to study were among factors predicting amount of change toward liberalism.

Although surprisingly small, the research base since the 1970 Chickering study generally confirms that college has a liberalizing effect on students' political views (Dey, 1988; Lottes \& Kuriloff, 1994; Wylie \& Parcell, 1981). However, Rich (1977) found this movement toward liberalism to be no greater for college students than for a noncollege comparison group. Thus, young adulthood in general may represent a developmental period particularly conducive to questioning societal values. Students' area of study also may predict amount of change toward liberalism. For example, Wylie and Parcell (1981) reported that students in sociology courses showed greater pre- to post-course change toward liberalism than did students in 
psychology courses. Dey (1988) concluded that the liberalizing effect of college is neither large nor universal and may be due more to socialization among students having different values than to academic stimulation in college courses. Nonetheless, in a relatively recent study of Ivy League students, Lottes and Kuriloff (1994) found that seniors scored higher than freshmen not only on liberalism but also on social conscience, tolerance of homosexuality, and feminist attitudes.

\section{College Students' Voting Patterns in 2004 Presidential Election}

Voting patterns of college students in the 2004 presidential election give some hint as to the more recent relationship between the college experience and students' political orientations. At the very least, one would expect the college experience to increase student participation in the political process. One national poll of college students taken by phone a few days after the 2004 presidential election confirms this expectation to be on target (Niemi \& Hanmer, 2004). Nearly $90 \%$ of the students reported they had registered to vote, and nearly $90 \%$ of those registered reported they actually voted ( $77 \%$ of college students overall). This rate of voting (77\%) was much higher than that of all 18- to 24-year olds (approximately 42\%), which included both college and noncollege adults in this age range. One may extrapolate from these data that probably twice as many college students voted as their noncollege peers. However, one major limitation of the Niemi and Hanmer report on the voting patterns of college students in the 2004 presidential election was its inclusion of only 1,200 students in the survey.

Although college students voted at a high rate in the 2004 election according to the Niemi and Hanmer (2004) report, did their votes represent a liberal preference? Given that the conservative presidential candidate won the popular vote, the electoral vote, and a substantial majority of the states, one might expect the voting pattern of college students to reflect this overall inclination toward political conservatism. Among students who voted, 55\% reported voting for the democratic candidate and $41 \%$ for the republican candidate. These percentages are very similar to those of 18- to 24-year olds irrespective of college status: $56 \%$ voted for the democratic candidate and $43 \%$ for the republican candidate. Apparently, the noncollege young adults voters shared a liberal preference with their same-age peers attending college. Contrast these democrat-republican percentages for college students 
who voted with those who did not vote: $45 \%$ of the nonvoters favored the democratic candidate and $44 \%$ the republican candidate. Thus, to some degree being politically active while in college (at least voting) appears to be associated with a more liberal orientation.

Although the Niemi and Hanmer (2004) report did not identify the percentage of students who classified themselves as democrats, republican, and independents, one may assume from other national polls that a substantial percentage of college students would classify themselves as independents. A CNN exit poll (2004) reported that 26\% of those who voted in the general election were independents. Inasmuch as the independent vote was heavily contested and evenly split (49\% for the democratic candidate and $48 \%$ for the republican candidate) in the general voting population, one wonders if college independents reflected the same political parity. That was not the case. Among the college independents who voted, $62 \%$ voted for the democratic candidate and $27 \%$ voted for the republican candidate. This ratio may suggest that college is either attracting more liberal-minded young people or is having a liberalizing effect on the more independent-minded youth.

A nationwide survey conducted by the Higher Education Research Institute at UCLA in 2004 (Sax et al., 2004) found that $26.1 \%$ of college freshmen identify themselves as liberal, $21.9 \%$ as conservatives, and $46.4 \%$ as "middle-of-the-road" (presumably independent). Given that independents in the Niemi and Hanmer (2004) survey overwhelmingly voted democratic in the 2004 presidential election, combining the findings of the Sax et al. and the Niemi and Hanmer (2004) reports suggests that a substantial majority of college attendees may be open to liberal political thinking. Thus, although most students do not come to college prepackaged as liberals, a majority appear to vote for more liberal candidates during college.

Previously cited research (Wylie \& Parcell, 1981) has suggested that college students' area of study is somewhat related to their political preferences. This finding was updated in the Niemi and Hanmer (2004) report. Among college students who voted in the 2004 presidential election, support for the democratic candidate was highest in the arts and humanities (66\%) and social sciences (63\%). Conversely, support for the republican candidate was highest in education (51\%), sciences (46\%), and business (46\%). However, only in education did the republican candidate receive a slightly higher percentage of votes than did the democratic candidate. The latter finding seems counter to the political record of the National Education Association (NEA), which traditionally has contributed far more to democratic than republican 
organizations and candidates (Escalante, n.d.). Nonetheless, Escalante claimed that only $49 \%$ of NEA members report belonging to the democratic party, leaving $51 \%$ to be aligned with republican and independent perspectives.

What issues had the greatest effects on the votes of college students in the Niemi and Hanmer (2004) report? Similar to the principal issues for the general voting population $(\mathrm{CNN}, 2004)$, moral values reflected the number one issue for college voters: $22 \%$ in the general population and $25.7 \%$ in the college population. Emphasis on moral issues had much the same political impact on college voters as on voters in the general election: $80 \%$ of voters in the general population who gave primacy to moral issues voted for the republican candidate, whereas $60 \%$ of the college voters who emphasized moral issues voted for the republican candidate. One clear distinction between college and general-population voters was the issue of the war in Iraq. Only $15 \%$ of the voters in the general election indicated that the war in Iraq was the major determinant of their vote $(73 \%$ of these individuals voted for the democratic candidate and $26 \%$ for the republican candidate), whereas $21.6 \%$ of the college voters saw Iraq as the principal determinant of their vote. Fifty-one percent of the college voters opposed the decision to go to war in Iraq, compared to $46 \%$ in the general voting population (CNN, 2004). Considered collectively, findings about the voting patterns of college students suggest the college experience may affect college students' voting preferences. This can best be accomplished by cultivating a climate of open and fair exploration of the major issues on which college students base their votes.

\section{Discussion of Unpopular Societal Perspectives}

Overall, the Niemi and Hanmer (2004) report suggests that the liberalizing effect of the college experience has largely survived more recent conservative pressures in the general U.S. population. Inasmuch as political preferences are replete with human rights issues, professors apparently are still finding a way to influence students' perspectives on those issues. How far can professors go in addressing the most controversial human rights issues in their courses? If they are to promote human rights that transcend the status quo, must they foster discussion of possibilities counter to societal mores and even to current laws? Ayers (1996) asserted that "the scope of academic freedom allows for pursuit of ideas that some members of society 
may consider inappropriate or offensive" (p. 2). This is where higher education is most likely to incur the wrath of a conservative support base. Because the very discussion of unconventional practices may be interpreted as implicit endorsement of those practices, a conservative constituency may challenge the right of higher education to engage in open discussion of some polarizing issues in society.

Some issues that have been debated for decades in society (such as causation for homosexuality and the rights of homosexuals) are still sensitive moral/political issues, given the religious and moral interpretations many conservatives attach to these issues. Examining the psychological research on such issues as the origin of homosexuality could be viewed by conservatives as advocating homosexuality. The voting patterns in the 2004 presidential election confirmed a link between sexual orientation and political ideology. In that election, homosexuals and bisexuals overwhelmingly supported the liberal candidate, whereas heterosexuals slightly favored the conservative candidate (CNN, 2004). Thus, facilitating open discussion of how individuals develop their sexual orientation could be viewed by many heterosexuals, especially the more politically conservative, as aligned with a liberal ideology.

Given the longstanding and unresolved sensitivity of many Americans toward homosexuality, the prospect of legalizing gay marriage has caused much public outrage even in some traditionally liberal states. So if professors wish to be proactive in changing the political mores of our society, gay marriage would present a provocative issue for class discussion. Inasmuch as many sociology and psychology courses address marriage and family issues, alternative models of marriage would seem a legitimate area for discussion. In addressing such controversial issues as gay marriages, an instructor might help students identify why they feel threatened by alternatives to the status quo. For example, would recognizing gay marriage as an alternative model of marriage be tantamount to morally endorsing gay marriage? Could gay marriages become so widespread that they would eventually threaten the primacy of heterosexual marriages? Would allowing gays to marry and have the legal rights associated with marriage undermine others' personal right to have a traditional, heterosexual marriage? Obstructions to full equality for homosexuals, even in the area of marriage, may eventually be regarded much as many now view racial and gender discrimination. How quickly and fully that comes to pass will depend, in part, on the extent and depth of discussion of such issues in college classes. 


\section{The Possibility of an Apolitical, Amoral, and Areligious Higher Education}

Many issues that could be fruitful for discussion in college classes have obvious political ramifications: military armament in the United States and elsewhere, preemptive warfare, military occupation of other countries, military establishment of democracies in other countries, civil liberties, patriotism, nationalism, internationalism, environmentalism, taxation, national spending, abortion, sexual orientation, gay marriages, and gun control. Individuals can hardly speak a word on these issues without revealing their political leaning. Even bringing up the issues for discussion may imply one's political orientation. So to achieve an apolitical climate in higher education classes would mean that many of the most important issues facing society could not be discussed openly or perhaps even mentioned.

In addition to the obvious political issues, other important societal issues have more subtle political agendas (e.g., social security, health care, preschool education, and renewable energy sources). Legislation with respect to these issues can affect individuals and society in profound ways. When legislation is proposed regarding such issues, one needs to ask who will benefit and how they will benefit from the proposed legislation. Are the most advantaged or the most disadvantaged sectors of society likely to benefit more from the legislation? How will the legislation affect the quality of life for future generations in the United States? Likewise, how will the legislation affect the quality of life in the poorer regions of the world? To what degree will the legislation place the responsibility for addressing the greatest human problems on society as opposed to the individual? How will big business be affected by the proposed legislation? Is there a hidden agenda counter to the public agenda for the proposed legislation?

One of the biggest issues facing our nation is the impact of our collective life style on our physical environment. Although environmental priorities are often posed as counter to the economic needs of our nation (which typically are considered over the short run), being the largest consumer of the world's most vital natural resources and the greatest producer of greenhouse gases puts our nation on a catastrophic course with destiny (Emission of Greenhouse Gases, 2005; Population and Natural Resources, n.d.). The impact of this combination is exacerbated by the United State's having the highest population growth rate of all developed countries (U.S. Population, n.d.). To fail to address these problem areas in college classrooms would be to forego one of our greatest missions as educators to help individuals and society find a 
way to live that will benefit the greatest number of people both now and in the future.

An apolitical, areligious, and amoral college education is probably not possible unless we are willing to circumvent the greatest issues of our time. What we are teaching in higher education, and at all education levels for that matter, must have application to the greatest problems of the world community. We cannot address these issues without examining the political, religious, and moral underpinnings of those issues. We can research these issues, expose students to that research, present both sides of controversial issues, help students understand and appreciate alternative perspectives, teach them how to present their own views in a convincing and respectful fashion, and ultimately provide a moral and intellectual climate for considering societal decisions that serve the greatest good for all people in current and future generations. Although professors may refrain from stating their personal views in class discussion of sensitive political issues, they cannot avoid or prohibit discussion of those issues if higher education is to contribute to a more humane society.

\section{Concluding Observations Regarding Political Disparity in Higher Education}

Some groups favoring close surveillance of professorial use of academic freedom have suggested that the imbalance between the number of democrats and republicans on university faculties is ipso facto evidence of systemic discrimination in hiring, tenure, and promotion practices in higher education (Horowitz \& Lehrer, 2002). These groups contend that predominantly democratic faculties reputedly hire, retain, and promote democratic faculty members, whereas excluding equally well-qualified instructors of a more conservative persuasion. Although I am not aware of any independent research that confirms political bias in personnel practices affecting professors in higher education, Horowitz (2003) contended that the absence of credible research on political bias in higher education is itself evidence of that bias. Consequently, Horowitz mainly referenced anecdotal events to support his claim of political discrimination in higher education.

Other possible contributors to the disparity in the political ratio of democrats to republicans in higher education include the intellectual level, intellectual style, and educational level of political liberals and conservatives in the United States. Is it possible that superior 
intellectual skills and an open intellectual style contribute to the likelihood of advanced graduate study, which in turn would qualify one to pursue university teaching as a career? Are the intellectual demands inherent in liberalism the same factors that attract one to university teaching? Thus, it is possible that the imbalance in the political party ratio among professors is fundamentally anchored in intellectual aptitude and style. Certainly, these are questions and possibilities that beg for independent research.

\section{References}

Academic Bill of Rights. (n.d.). Retrieved March 11, 2005, from http://www.students foracademicfreedom.org/abor.html

Altemeyer, B. (2003). Why do religious fundamentalists tend to be prejudiced? International Journal for the Psychology of Religion, 13, 17-28.

Altemeyer, B., \& Hunsberger, B. (1992). Authoritarianism, religious fundamentalism, quest, and prejudice. International Journal for the Psychology of Religion, 2, 113-133.

Ayers, B. S. (1996). The effects of social ideology on academic freedom (Report No. HE030444). Greensboro, NC: National Center for Higher Education. (ERIC Document Reproduction Service No. ED411725)

Bain, S. K., Williams, R. L., Isaacs, R., \& Williams, A. (in press). Undergraduates' evaluations of developmental claims and their identification of information sources. Innovative Higher Education.

Bollinger, L. (2005). Academic freedom. Annual Benjamin N. Cardozo Lecture, Association of the Bar of the City of New York. Retrieved August 6, 2005, from $\mathrm{http} / / / \mathrm{www} . c 0 l u m b i a . e d u / c u / p r e s i d e n t / c o m m u n i c a t i o n s \%$ files/cardozolecture.htm

Campfield, S., \& Finney, R. (2005). House Bill 432 and Senate Bill 1117: An act to amend Tennessee Code Annotated, Title 49, Chapter 7, Relative to higher education. Nashville, TN: Tennessee State Legislature.

Chickering, A. W. (1970). Civil liberties and the experience of college. Journal of Higher Education, 41, 599-606.

CNN. (2004). U.S. president/national/exit poll. Retrieved December 19, 2004, from http://www.cnn.com

Copeland, T. V. (1995). The relationship of Protestant fundamentalism and intellectual and moral development among college students. Dissertation Abstracts International Section A: Humanities and Social Sciences, 56(1A), 0141.

D'Eon, M., \& Proctor, P. (2001). An innovative modification to structured controversy. Innovations in Education and Teaching International, 38, 251-256.

Dey, E. L. (1988, November). College impact and student liberalism revisited: The effect of student peers. Paper presented at the Annual Meeting of the Association for the Study of Higher Education, St. Louis, MO.

Don't let lawmakers into college classrooms. (2005, April 5). Knoxville News Sentinel, B4.

Energy Information Administration. (2005). Emission of greenhouse gases in the United States 2004. Retrieved February 27, 2006, from ftp://ftp.eia.doe.gov/ pub/oiaf/1605/cdrom/pdf/ggrpt/057304.pdf

Escalante, J. (n.d.). I thought the union was going to focus on how to improve our skills. But they're more interested in politics than kids. Retrieved August 11, 2005, from http://home.iae.nl/users/lightnet/world/awaken/neapolitics.htm 
Fish, S. (2003). A university is not a political party. The Chronicle of Higher Education. Retrieved from the Chronicle of Higher Education's Chronicle Careers web site http://chronicle.com/jobs

Herreid, C. F. (1996). Structured controversy: A case study strategy. Journal of College Science Teaching, 26, 95-101.

Horowitz, D. (2003). The campus blacklist. Retrieved August 7, 2005, from http://www. studentsforacademicfreedom.org/essaysblacklist.html

Horowitz, D., \& Lehrer, E. (2002). Political bias in the administrations and faculties of 32 elite colleges and universities. A report of the Center for the Study of Popular Culture. Retrieved March 12, 2005, from http://www.frontpagemag.com/Content/read.asp?ID55

Klein, D. B., \& Stern, C. (2004/2005). Political diversity in six disciplines. Academic Questions, 18(1), 40-52.

Klein, D. B., \& Western, A. (2004). How many democrats per republican at UC-Berkeley and Stanford? Voter registration data across 23 academic departments. Retrieved March 12, 2005, from http://lsb.scu.edu/-dklein/Voter/defautl.htm

Kohlberg, L. (1987). The development of moral judgment and moral action. In L. Kohlberg (Ed.), Child psychology and childhood education: A cognitive-developmental view (pp. 259-328). New York, NY: Longman.

Light, P. C. (2001). Government's greatest priorities of the next half century. Reform Watch, 4, Brookings Institution, Retrieved March 12, 2005, from http:// www.brookings.edu/dybdocroot/com/reformwatch/rw04/rw4.pdf

Lindholm, J. A., Astin, A. W., Sax, L. J., \& Korn, W. S. (2001-2002). The American college teacher: National norms for 2001-2002 HERI faculty survey. Los Angeles, CA: Higher Education Research Institute, UCLA Graduate School of Education.

Lottes, L. L., \& Kuriloff, P. J. (1994). The impact of college experience on political and social attitudes. Sex Roles, 31(1/2), 31-54.

Niemi, R., \& Hanmer, M. (2004). College students in the 2004 election. Circle: The Center for Information and Research on Civic Learning \& Engagement. College Park, MD: School of Public Policy, University of Maryland.

Paul, R., \& Elder, L. (2003). How to detect media bias \& propaganda. Dillon Beach, CA: Foundation for Critical Thinking.

Pope, J. (2004, Dec. 27). Academic freedom: Are conservative students dictating what they don't want to be taught? Knoxville News Sentinel E2.

Population and natural resource (n.d.). AAAS atlas of population \& environment. American Association for the Advancement of Science. Retrieved August 7, 2005, from http://atlas/aaas.org/index.phy?part $=2$

Reimer, S., \& Park, J. (2001). Tolerant (in)civility? A longitudinal analysis of white conservative Protestants' willingness to grant civil liberties. Journal for the Scientific Study of Religion, 4, 735-745.

Rich, H. E. (1977). The liberalizing influence of college: Some new evidence. Adolescence, $12,199-211$.

Sax, L. J., Hurtado, S., Lindholm, J. A., Astin, A. W., Korn, W. S., \& Mahoney, K. M. (2004). The American freshman: National norms for fall 2004. Los Angeles, CA: Higher Education Research Institute, UCLA Graduate School of Education \& Information.

Students for academic freedom second year achievement report. (2005). Retrieved August 7, 2005, from http://www.studentsforacademicfreedom.org/letters/Letters Jan-may2005/letter-secondyearachievement

Tozer, S. E., Violas, P. C., \& Senese, G. B. (1995). School and society: Historical and contemporary perspectives. New York, NY: McGraw Hill.

U.S. population and the environment. (n.d.). Retrieved August 7, 2005, from http://www.susps.org/overview/population.html

Williams, R. L., Bain, S. K., Stockdale, S., Isaacs, R., \& Williams, A. (2003). Role of critical thinking in judging the accuracy and sources of claims in human development. Inquiry: Critical Thinking Across the Disciplines, 22, 65-72. 
Williams, R. L., Bliss, S., \& McCallum, S. (in press). Christian conservatism and militarism among teacher-education students. Review of Religious Research.

Wylie, M. L., \& Parcell, S. R. (1981, August). A study of attitude change in college classes. Paper presented at the Annual Meeting of the American Sociological Association, Toronto, Ontario, Canada. 